\title{
VITAL DA CUNHA, CHRISTINA; MENEZES, RENATA. RELIGIŌES EM CONEXÃO: NÚMEROS, DIREITOS, PESSOAS. COMUNICAÇÓES DO ISER, RIO DE JANEIRO, ANO 33, N. 69, 2014.
}

\section{Amanda Mendonçal}

O conjunto de onze artigos que integram a coletânea Religióes em conexão: números, direitos, pessoas aborda, por meio de diferentes perspectivas teóricas e situações empíricas, mudanças no lugar da religião na sociedade brasileira atualmente. A publicação tem início com artigos que utilizam o Censo decenal do IBGE discutindo o processo de inserção nele da categoria religião e sua relativa importância para a compreensão do fenômeno religioso no Brasil. Os textos trazem indagaçôes a respeito dos limites que se apresentam no uso dos dados veiculados pelo recenseamento e as disputas políticas que se constroem em torno dos números divulgados. No entanto, a incorporação desses dados do Censo contribuem para inúmeras análises sobre o campo religioso no Brasil.

É o caso do artigo Os limites do censo no campo religioso brasileiro, de Maria Goreth Santos, em que é exposto que o número de declarações religiosas vem revelando mudanças no perfil da religiosidade brasileira nas últimas três décadas. Através de uma breve reconstrução histórica do recenseamento da religiosidade dos brasileiros, que é realizado desde 1872 e que foi assumido pelo IBGE na década de 1940, a autora procura analisar de que maneira as informações produzidas pelo recenseamento vêm se modificando e contribuindo com os estudos da religião no Brasil. Até o Censo de 1970, por exemplo, divulgava-se apenas os dados dos principais

1 Doutoranda em Política Social no CPGESS/UFF, Mestre em Educação e Socióloga, formada pela Universidade Federal do Rio de Janeiro/UFRJ e pesquisadora atuante no campo da laicidade e das políticas educacionais. Contato: amandademendonca@gmail.com

Debates do NER, Porto Alegre, Ano i6, N. 27, P. 439-449, JAn./Jun. 2015 
grandes grupos religiosos existentes no país e somente na década seguinte começaram a aparecer as declaraçōes em forma de denominações. Entretanto, as dificuldades de conciliar objetividade dos números com as subjetividades do campo religioso resultaram, segundo a autora, em modificações na metodologia do Censo no quesito religião.

Esta questão também está presente no texto de Marcelo Camurça, $A$ religião e o censo: enfoques metodológicos. Uma reflexão a partir das consultorias do ISER ao IBGE sobre o dado religioso nos Censos, que evidencia as dificuldades de classificar a diversidade de denominações que o Censo de 1991 apresentou no quesito pertencimento religioso e a assessoria que se estabeleceu com o ISER em busca do desenvolvimento de uma tipologia que comportasse ao máximo a pluralidade de religiôes declaradas pela população brasileira. Já com novas categorias, os dados estatísticos do IBGE do Censo de 2000 passaram a ser incorporados cada vez mais nas análises dos cientistas sociais sobre a realidade da sociedade brasileira. Soma-se a isso o fato de que a difusão dos dados sobre religião dos Censos do IBGE adquiriu espaço relevante na mídia brasileira, o que tem gerado, para o autor, uma influência desses dados na opinião pública sobre as religiōes no Brasil e uma preocupação de agrupamentos religiosos em relação aos números divulgados. Este fenômeno faz com que a questão operacional do recenseamento e o anúncio dos resultados não se restrinjam mais apenas aos institutos responsáveis pela pesquisa, mas ao conjunto geral da sociedade.

$\mathrm{O}$ artigo de Renata de Castro Menezes, Religióes, números e disputais sociais, também traz reflexões em torno da produção, da divulgação e da repercussão dos dados sobre religião nos Censos, procurando entender porque essa visualização do perfil religioso nacional se tornou uma questão relevante para tantos. Para a autora, o Censo é uma fotografia de autodeclaração religiosa em determinado contexto, que não possibilita qualificar a mudança, ou entender suas nuances, mas apenas auxilia a visualização das macrolinhas das transformaçóes de uma década. As categorias do censo produzem um efeito de reificação e há, portanto, uma relação intrínseca entre Censo e poder estatal, que é a de subsidiar as açôes do Estado. Assim, 
é possível compreender que o Censo se torne um campo de disputas, já que tem um papel fundamental na representação e legitimação de grupos e no estabelecimento de políticas públicas.

Os textos convergem no sentido de apontar que os números do Censo provocam efeitos muito além do campo do conhecimento, influindo na construção de identidades, no desenvolvimento de políticas públicas, e até mesmo no estabelecimento de alianças partidárias. Contudo, mesmo atentando para os limites da compreensão das mudanças no campo religioso brasileiro, não se pode anular sua capacidade de produzir uma "imagem de comunidade", afinal trata-se de uma construção em escala nacional e de impulsionar análises realizadas por múltipos campos de conhecimento acerca do pertencimento religioso.

Ainda sobre o uso do recenseamento o artigo Campo religioso em transformação, de Faustino Teixeira, aprofunda a análise acerca da atual situação do campo religioso brasileiro a partir de uma comparação dos dados de 2000 e 2010 divulgados pelo IBGE. Destaca que o aumento da população brasileira em cerca de 21 milhões de pessoas não incrementou o catolicismo. Para o autor, pode-se dizer que o catolicismo romano é "religião da maioria dos brasileiros", mas não mais a "religião dos brasileiros". Assim, conclui-se dos artigos mencionados, que essa nova situação do catolicismo apenas confirma a progressiva tendência de pluralização do campo religioso nacional.

Segundo o autor, a diversificação religiosa encontrada no Brasil está diretamente relacionada ao importante crescimento evangélico nas últimas décadas, em especial aos pentecostais, que respondem por mais de dois terços do total de evangélicos. Contudo, essa progressiva pluralização religiosa veio acompanhada de uma crescente desinstitucionalização religiosa, com enfraquecimento das filiações tradicionais. $\mathrm{O}$ texto de Teixeira, também analisa as mudanças que vêm ocorrendo na relação de identidade e vínculo dos fiéis às suas instituições religiosas, já que esse acredita que esta é forma de se compreender a presença da religião ou do dinamismo religioso na contemporaneidade. Para ele, há que se reconhecer que a modernidade

Debates do NER, Porto Alegre, Ano i6, N. 27, P. 439-449, JAn./Jun. 2015 
não suscitou, como se esperava, o declínio da religião, ou seja, o avanço da modernidade não produziu uma menor presença da religião, mas outra forma de dinâmica religiosa que envolve mudanças substantivas no "lugar institucional" da religião e uma presença pública da religião na cena brasileira.

Ainda acerca destas transformaçóes envolvendo uma nova dinâmica e vínculos religiosos o artigo de Silvia Regina Alves Fernandes, O censo não diz tudo, mas que ajuda, ajuda... - O catolicismo em cidades do estado menos católico, afirma que o processo de migração e mobilidade humana constitui-se como uma variável importante para a compreensão dessas mudanças em torno do papel institucional ocupado atualmente pelas religiōes na vida da população. Para a autora, é preciso considerar os fenômenos que ocorrem na vida das pessoas na ordem do cotidiano que são capazes de conduzir os indivíduos a diferentes experimentaçōes do religioso, pontuando sempre a necessidade de se buscar correlaçôes das variáveis econômica, social e cultural, além da subjetividade individual a respeito dessas interpretações.

A partir dos dados ofertados pelos últimos Censos, Fernandes explora o declínio proporcional histórico na representação dos católicos no Brasil, utilizando os números referentes à região sudeste como fonte explícita da questão da heterogeneidade recente do campo religioso e do declínio católico, articulando estes elementos à dinâmica migratória na região. A hipótese desenvolvida no texto é de que toda a circulação de pessoas e experiências que fazem no decorrer de suas vidas em termos de acesso a novas tecnologias, relações afetivas, trabalho e lazer são potenciais fatores de influência que alteram a relação com a religião. Nesse sentido, torna-se relevante o reconhecimento da atitude de experimentação religiosa como uma prática contemporânea e o olhar atento sobre os contextos socioculturais na análise dos dados censitários sobre religião no Brasil.

Esta relação entre vínculos religiosos, traços característicos da modernidade e a atuação do Estado nas mais diferentes esferas enquanto elementos de extrema relevância para a análise do papel da religião na sociedade contemporânea norteiam a segunda parte da publicação. No artigo Esfinge 
da UPP e os oráculos da religiāo: Percepção de lideranças religiosas nativas sobre unidades de polícia pacificadora em favelas cariocas, de Clemir Fernandes Silva, que trata, por exemplo, da nova política de segurança pública do Estado do Rio de Janeiro, é possível identificar esta preocupação através da análise de conflitos religiosos produzidos por agentes estatais e atores religiosos específicos nos processos de implementação das UPPs. O objetivo é destacar a dimensão da religião a partir da percepção de lideranças religiosas nativas das áreas com UPP acerca de sua presença e ação local, fazendo uma ligeira comparação com outro tipo de dominação, a do tráfico armado. A premissa é de que grupos religiosos detêm capilaridade, reconhecimento e legitimidade por sua presença, condição assimétrica da UPP, que não possui sólida estrutura institucional. Em suma, o que o artigo busca demonstrar é que mesmo tendo amparo legal, por ser uma força instituída pelo Estado democrático, a UPP carece de sustentação, reconhecimento e legitimação social, apresentada pelos segmentos religiosos.

Tratando de outra esfera, mas ainda trazendo a discussão sobre o papel do Estado, temos o texto assinado por Sandra de Sá Carneiro, Ensino religioso no Rio de Janeiro. É um bom caso para se pensar religião, direitos humanos e as relações entre Estado e igreja”, pois aborda a implantação do ensino religioso no estado do Rio de Janeiro problematizando as relaçōes entre Estado e religião. Através do debate público, que envolve agentes religiosos e laicos, alunos, professores e representantes do Estado, percebe-se que a presença da religião na escola serve como ponto de partida para a compreensão das disputas do campo religioso brasileiro, bem como o lugar da religião na esfera pública na atualidade. A autora defende ainda que o oferecimento do ensino religioso nas escolas públicas acoberta uma série de questôes, como as que envolvem os distintos sentidos atribuídos à noção de laicidade do Estado, bem como a liberdade religiosa garantida pela constituição.

Ao longo dos textos, também é possível identificar o debate acerca da crescente participação religiosa no espaço público brasileiro. $\mathrm{O}$ artigo Religião e política. Algumas consideraçôes sobre conflitos e posiçôes, de Paulo Victor Lopes, traz esta discussão a partir das dificuldades enfrentadas pelas

Debates do NER, Porto Alegre, ANo I6, N. 27, P. 439-449, JAn./Jun. 2015 
pautas feministas e LGBT hoje em dia no cenário nacional e a relação destas com a ação de forças religiosas, mais notadamente cristãs. Sobre este "embarreramento" das pautas vinculadas diretamente ao campo dos Direitos Humanos, o autor chama atenção para o fato de que não é o cristianismo em si (seja o católico ou evangélico) que se torna um empecilho para a garantia de direitos às mulheres ou LGBT, mas uma expressão específica, um agente entre outros. Este é um ponto comum ao conjunto de textos, a ideia de que não se pode homogeneizar a atuação pública de uma denominação religiosa. É preciso considerar as diferenças internas, as especificidades de cada uma e ainda a trajetória dos agentes que as representam. Esta perspectiva presente na publicação apresenta-se com uma crítica a análises do campo religioso brasileiro e sua atuação na cena pública nacional que consideram os religiosos como únicos responsáveis pelo conservadorismo presente na esfera pública brasileira.

Entretanto, é importante destacar que essa perspectiva não desconsidera que estes agentes religiosos vêm influenciando de forma expressiva o cenário nacional, ganhando espaço no Executivo e sendo atores fundamentais nas eleições e em barganhas características de algumas casas legislativas. Soma-se a isso o fato destacado no texto de Lopes de que a atuação de segmentos religiosos no espaço público brasileiro tem conduzindo a uma desumanização de determinados segmentos sociais, o que, como consequência, dificulta a conquista de direitos.

Outro texto que contribui com esse debate sobre o religioso e o Estado na contemporaneidade e os conflitos gerados na sociedade brasileira é o de Ana Paula Mendes de Miranda, Como se discute religiāo e política? Controvérsias em torno da "luta contra a intolerância religiosa" no Rio de Janeiro, que trata de processos de mobilização em torno dos conflitos relativos à intolerância religiosa no Rio de Janeiro, formulação e implementação de políticas públicas, no âmbito do governo estadual. Como no Brasil não existe tipificação para intolerância religiosa, o artigo toma como referência o destaque que a mesma passou a ocupar na esfera pública no Rio de Janeiro a partir da composição de uma câmara de combate à intolerância religiosa.

Debates do NER, Porto Alegre, ANo I6, N. 27, P. 439-449, JAn./Jun. 2015 
O texto parte da premissa de que embora a liberdade religiosa tenha sido consagrada como um direito civil básico relacionada à liberdade de expressão, os agentes públicos optam por não intervir nos conflitos, mesmo quando estes se revelam atentatórios ao direito das pessoas ou ao funcionamento da sociedade (Miranda, 2012 apud Vital da Cunha; Menezes, 2014), o que contribui para a ressignificação da expressão intolerância religiosa, no contexto atual, como uma bandeira de luta capaz de suplantar diversidades em função de uma experiência vivida de insulto moral.

O artigo também retoma a discussão enunciada anteriormente nos outros textos acerca da construção do espaço público no Brasil, que se deu de forma hierárquica e desigual, e propiciou que se constituísse uma arena pública, na qual as regras de acesso aos bens disponibilizados pelo Estado não são gerenciadas de forma universalista e igualitária para todos os credos, por exemplo. Nesta perspectiva, Miranda defende que a construção de uma agenda política voltada para a luta contra a intolerância representa, portanto, uma estratégia de lidar com um Estado idealizado, no qual a segurança e a justiça deveriam trabalhar para garantir os direitos, sem se defrontar com as limitaçôes práticas que as pessoas enfrentam ao demandar uma causa a essas instituições.

Em suma, nota-se que o que o conjunto de textos busca evidenciar é a relação envolvendo o campo religioso brasileiro na atualidade, suas mudanças e possibilidades metodológicas de análise, e a noção de democracia. Esse debate fica explícito no artigo Religióes $x$ democracia?: Reflexóes a partir da análise de duas frentes religiosas no Congresso Nacional, de Christina Vital da Cunha, que propõe uma reflexão sobre laicidade e democracia em disputa, contrapondo resultados de duas pesquisas realizadas pela autora, uma sobre a Frente Parlamentar Evangélica e outra sobre a Frente Parlamentar Mista em Defesa dos Povos Tradicionais de Terreiros. A perspectiva que norteia o texto é a compreensão de que a esfera pública brasileira é constituída pelo elemento religioso. Assim como no artigo de Lopes, a autora chama atenção para a atuação diversa de religiosos na política, ainda que seja enfatizada mais a sua uniformidade conservadora, não há a pretensão de questionar a legitimidade da presença de religiosos na política, mas ressaltar suas diferentes performances.

Debates do NER, Porto Alegre, ANo I6, N. 27, P. 439-449, JAn./Jun. 2015 
Para realizar tal discussão, Vital da Cunha apresenta os dados das pesquisas que referenciaram o artigo, destacando os mecanismos e as técnicas de operação política dos integrantes da Frente Evangélica e os argumentos utilizados na arena pública na direção de algumas minorias, bem como em relação aos integrantes da Frente Parlamentar em Defesa dos Povos Tradicionais de Terreiro. Em outra seção do artigo, são feitas conexões entre as informações apresentadas, confrontando-as às consideraçōes que produzem a equalização entre direita, conservador, religioso e antidemocrático. Destaca-se ainda neste debate o fato de que os integrantes de ambas as frentes afirmam a importância do seu lugar no parlamento articulando a existência delas à força da democracia e da laicidade no Brasil.

A partir desta perspectiva, o artigo sugere que a existência dessas frentes religiosas significaria novos segmentos organizados e legitimamente ocupando uma cadeira no Congresso, confrontando a histórica hegemonia católica no Brasil e marcando o que seria uma ampliação do acesso a bens políticos. Uma reflexão importante trazida pelo texto é a de que o sentido de democracia e de laicidade empregado por estas frentes, por exemplo, para justificar sua atuação pública, é absolutamente compatível com as noções contemporâneas de democracia representativa, na qual diferentes atores sociais ocupam espaço de poder. Assim, os religiosos enquanto representantes legítimos de grupos que compõem a sociedade têm direito de ter seus representantes no cenário público brasileiro.

Entretanto, esta representação vem sendo alvo de preocupação e de inúmeras críticas por parte de segmentos pró laicidade. Nesse sentido, o texto de Vital da Cunha propõe analisar tal ponto a partir da seguinte questão: Qual o incômodo da presença religiosa na política? Para respondê-la, a autora resgata a relação entre Estado e religiōes no Brasil e a verificação de um aparelhamento do Estado por instituiçôes religiosas, em especial a Igreja Católica, que foi beneficiada com diferentes dispositivos ao longo das Cartas Magnas brasileiras. Mas, o que o artigo busca destacar é o fato de que este aparelhamento do Estado no Brasil não é operado exclusivamente por alguns religiosos, sendo este revelador da relação estabelecida no país entre público e privado. 
Outra questão explorada ao longo do artigo diz respeito à associação realizada frequentemente entre religioso e conservadorismo. Os dados trazidos pela comparação entre a atuação de parlamentares religiosos das frentes pesquisadas emerge como meio de deslocar essa amalgama presente no imaginário social e explorado grandemente na mídia entre religiosos, direta, conservadorismo. Tornar-se-ia necessário, segundo a autora, considerar trajetórias pessoais e políticas e de não atribuir exclusivamente ao pertencimento religioso a formação de atores conservadores ou de direita. Além da mudança nacional no perfil daqueles identificados com a direita no Brasil, pesquisas presentes no artigo destacam isso, assiste-se atualmente no contexto político mundial ao crescimento e/ou uma maior publicização do discurso moralista e conservador.

Em contraposição a esse discurso conservador presente na arena pública brasileira, há a incorporação cada vez maior da questão do respeito à diversidade pelo Estado e pelas políticas públicas. Nesta perspectiva, o artigo de Regina Novaes, Em nome da diversidade. Notas sobre novas modulaçôes nas relaçóes entre religiosidade e laicidade, traz um interessante debate sobre o uso dessa expressão, refletindo sobre o lugar que a ideia de diversidade ocupa no estoque de argumentos que justificam aproximaçôes e/ou distanciamentos entre as religiōes e o poder público. A autora destaca que o atual reconhecimento da diversidade como um "valor" central é resultado de uma progressiva tomada de consciência em relação à globalização e uma crescente atenção dada à natureza interconectada das questóes culturais, políticas, econômicas e sociais.

O texto também aponta para o fato do discurso sobre diversidade ter se tornado um universo de disputas, um termo ou expressão que pode abarcar posições políticas até mesmo contraditórias. São inúmeras concepções de diversidade em jogo e no campo religioso as experiências de diálogo inter-religioso e do valor da diversidade esbarram, segundo a autora, em hierarquias historicamente construídas nesse campo. A laicidade também acaba se tornando um objeto de disputa entre agentes, sejam eles mais ou menos resistentes ao reconhecimento da diversidade religiosa. Ou seja, nos dias atuais, as inter-relações entre religiosidade, laicidade e diversidade envolvem também outras dimensões subjetivas e objetivas.

Debates do NER, Porto Alegre, ANo I6, N. 27, P. 439-449, JAn./Jun. 2015 
O artigo de Novaes explora esta perspectiva a partir da análise de experiências no campo das políticas públicas de juventude, em que o pertencimento religioso também passou a ser reconhecido como parte da diversidade das juventudes brasileiras. Nota-se nos espaços de juventude um espraiamento do recorte religioso, com grupos que se apresentam na cena pública a partir de vínculos com a dimensão religiosa disputando não só os espaços destinados aos segmentos religiosos, mas também outras cadeiras. Em resumo, os movimentos, as redes e os grupos juvenis também se deparam com o desafio de articular o reconhecimento, o pluralismo religioso e a laicidade do Estado. Nesse cenário, o direito à diversidade justifica a presença de jovens de diferentes grupos religiosos participando de espaços de articulação entre Estado e sociedade.

A proposta apresentada pelo texto, portanto, é contribuir com a discussão sobre as atuais relaçôes entre religiosidade e laicidade. Para tal, a autora traça uma comparação sobre as trajetórias dos conceitos de secularização e de diversidade religiosa, argumentando que, para falar em separação de religião e política, é preciso tratar de novas, tensas e delicadas relações entre pares. É necessário, por exemplo, levar em conta legislações, expedientes do poder publico. Nesse sentido, o artigo pontua que o "secularismo à brasileira" remete tanto à nossa história política, tecida por desigualdades sociais, quanto aos múltiplos pertencimentos religiosos subalternos sob hegemonia católica, e que, por conseguinte, não é possível compreender tal secularismo se não levar em conta o intrigante encontro entre o discurso global da diversidade e as mudanças recentes no campo político brasileiro e no campo religioso.

Assim, este conjunto de textos apresentados ajudam a pensar a religião como um fator que conforma as relações entre as pessoas e as instituiçôes estatais, especialmente no que se refere às formas de administração de conflitos. Dentro desse campo, a partir da ênfase em temáticas diversificadas e diferentes perspectivas teóricas, a publicação busca contribuir com o debate envolvendo religião, laicidade e democracia. Para isso, enfatizou em sua primeira seção a extrema relevância dos dados produzidos pelo Censo do IBGE, tanto os grupos formadores de opinião como a grande mídia e os pesquisadores na análise do papel da religião na sociedade contemporânea. 
Pontuando as críticas e marcando os limites do recenseamento, os textos de uma forma geral reconhecem a importância do uso do Censo no debate contemporâneo das ciências sociais sobre o campo religioso brasileiro.

A partir das análises da primeira seção, que apontaram para a complexidade do campo religioso brasileiro e que levam ao tema da laicidade, a publicação passa a tratar então de noções como secular, religioso, espaço público e diversidade enquanto questôes indissociáveis do debate sobre democracia na modernidade. A proposta é destacar as novas formas de abordagem do religioso destacando diferentes imbricações empíricas entre religião, sociedade, cultura, política e Estado, assim como expor a temática da secularização e do caráter religioso elou secular do Estado, apresentando suas implicaçôes e questôes mais recentes no conjunto da sociedade brasileira. Por fim, o conjunto de artigos aponta para a defesa da laicidade como uma forma de direcionar açóes políticas para as discussões ideológicas a respeito das diferentes formas de se relacionar com o religioso e de garantir valores e um modo de atuação universal que oriente as instâncias públicas estatais.

\section{REFERÊNCIA}

MIRANDA, Ana Paula Mendes. Como se discute religião e politica? Controvérsias em torno da "luta contra a intolerância religiosa" no Rio de Janeiro. In.: VITAL DA CUNHA, Christina; MENEZES, Renata. Religiōes em conexão: números, direitos, pessoas. Comunicaçôes do ISER, Rio de Janeiro, ano 33, n. 69, 2014.

VITAL DA CUNHA, Christina; MENEZES, Renata. Religiōes em conexão: números, direitos, pessoas. Comunicaçôes do ISER, Rio de Janeiro, ano 33, n. 69, 2014.

Recebido em: 09/02/2015

Aprovado em: 15/02/2015

Debates do NER, Porto Alegre, ANo I6, N. 27, P. 439-449, JAn./Jun. 2015 